\title{
Impact of visualization on simulation training for vascular anastomosis
}

\author{
Tarek Malas, MD, CM, MPH, FRCSC, ${ }^{\mathrm{a}}$ Talal Al-Atassi, MD, CM, MPH, FRCSC, ${ }^{\text {a }}$ \\ Tim Brandys, MD, MEd, FRCSC, FACS, ${ }^{\text {b }}$ Viren Naik, MD, MEd, MBA, FRCPC, \\ Harry Lapierre, MD, FRCSC, ${ }^{a}$ and Buu-Khanh Lam, MD, CM, MPH, FRCSC ${ }^{\mathrm{a}}$
}

\section{ABSTRACT}

Objective: There is mounting evidence supporting the benefit of surgical simulation on the learning of skills independently and in a patient-safe environment. The objective of this study was to examine the effect of visualization of surgical steps via instructional media on performance of an end-to-side microvascular anastomosis.

Methods: Thirty-two first- and second-year surgical trainees from the University of Ottawa received an expert-guided, didactic lecture on vascular anastomosis and performed an end-to-side anastomosis on a procedural model to assess baseline skills. Assessments were performed by 2 blinded, expert observers using validated measurements of skill. Subjects were then proctored to perform anastomoses using the model. Subjects were then randomized to watch an instructional video on performance of vascular anastomosis using visualization as the education strategy. One week later, subjects were again assessed for technical skill on the model. The primary outcome was the score achieved on the Objective Structured Assessment of Technical Skill (OSATS) scale. Secondary outcomes included an anastomosis-specific End-Product Rating Score and time to completion.

Results: Compared with residents who received expert-guided simulator training alone, those who used the supplementary multimedia scored significantly greater on OSATS $(17.4 \pm 2.9$ vs $14.2 \pm 3.2, P=.0013)$ and on End-Product Rating Score $(11.24 \pm 3.0$ vs $7.4 \pm 4.1, P=.011)$. However, performance time did not differ between groups (15.7 vs 14.3 minutes, $P=.79$ ).

Conclusions: Residents with supplemental instructional media performed an end-to-side anastomosis more proficiently as assessed by OSATS and with a greater quality end-product. This suggests that both didactic simulation training as well as use of visualization multimedia improves learning and performance of vascular anastomosis and should be incorporated into surgical curricula. (J Thorac Cardiovasc Surg 2018;155:1686-93)

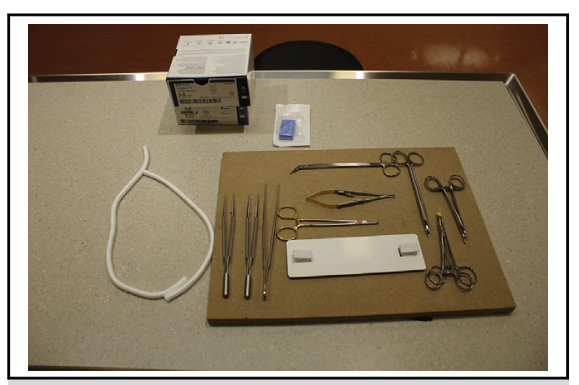

Bench model for vascular anastomosis (4-mm polytetrafluoroethylene grafts, Prolene suture, microvascular equipment)

\section{Central Message}

Trainees who watched a video performed vascular anastomosis more proficiently with greater quality, suggesting that simulation and visualization multimedia improves learning and should be integrated in curricula.

\section{Perspective}

Surgical training is challenged by work-hour restrictions, growing public scrutiny of surgical outcomes, increasingly complex cases, and a suboptimal high-stress environment. To facilitate teaching trainees important complex skills such as vascular anastomosis, we demonstrated that visualization multimedia, which has not been examined in a randomized study, has significantly improved their acquisition of skills.

See Editorial Commentary page 1694.
The traditional methodology of surgical education, pioneered by Dr John Halstead, involves learning skills in an operating room setting in a progressive fashion. Although this apprenticeship model has formed the backbone of

\footnotetext{
From the ${ }^{\mathrm{a}}$ Division of Cardiac Surgery, University of Ottawa Heart Institute, Ottawa, Ontario, Canada; and ${ }^{\mathrm{b}}$ Division of Vascular Surgery, and ${ }^{\mathrm{c}}$ Department of Anesthesiology, University of Ottawa/The Ottawa Hospital, Ottawa, Ontario, Canada.

Funded by a generous grant from the Department of Surgery at University of Ottawa. Received for publication Sept 22, 2016; revisions received Aug 31, 2017; accepted for publication Oct 21, 2017

Address for reprints: Buu-Khanh Lam, MD, CM, MPH, FRCSC, Department of Cardiac Surgery, University of Ottawa Heart Institute, 40 Ruskin St Room H3404, Ottawa, Ontario, Canada K1Y 4W7 (E-mail: bklam@ottawaheart.ca). 0022-5223/\$36.00

Copyright (c) 2017 by The American Association for Thoracic Surgery https://doi.org/10.1016/j.jtcvs.2017.10.080
}

most surgical residency training programs, multiple constraints limit this approach and can threaten the learning of operative skills. ${ }^{1}$ Implementation of work-hour restrictions has significantly reduced clinical exposure and educational opportunities. ${ }^{1-3}$ Furthermore, with growing public scrutiny of surgical outcome and an increasing complexity of surgical cases, surgeons are less inclined to engage residents, particularly in the face of time to

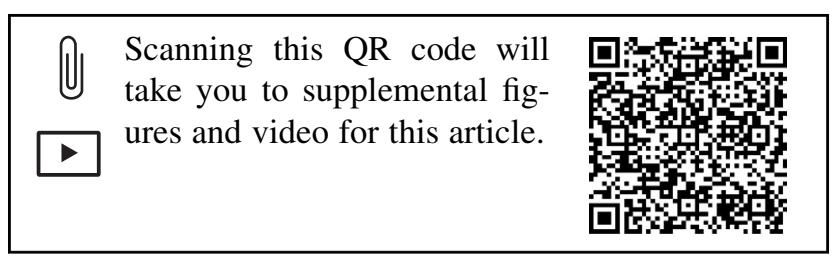




\section{Abbreviations and Acronyms \\ EPRS = End-Product Rating Score \\ OSATS $=$ Objective Structured Assessment of \\ Technical Skill \\ PGY = postgraduate year}

complete a surgical procedure safely and efficiently. ${ }^{4}$ These factors contribute to a high-stress environment that can be suboptimal for surgical education.

In response to these constraints, surgical simulation has emerged as a successful tool in the learning of surgical skills. $^{4-6}$ Simulation permits repetitive, independent training of skills in a patient-safe environment. In effect, the methodologic aspects of surgical skills education have considerably evolved over the past decade. There is mounting evidence in the literature to support the use of simulation in multiple surgical fields. ${ }^{5,7}$ Despite this evidence, however, the use of simulation is underdeveloped in the field of cardiovascular surgery.

Vascular anastomosis is an important skillset that is extensively used in cardiovascular surgery and in most surgical subspecialties. This complex procedure requires expertise in a wide range of skills: cognitive planning, instrument and suture handling, vascular tissue manipulation, and economy of motion. ${ }^{4}$ Similar to other studies, we have demonstrated significant improvement in the performance of vascular anastomosis in our previous study using simulation on a bench model. ${ }^{4,8}$ However, although independent simulation training tackles "mechanical" motor skills successfully, it often lacks in the development of cognitive factors involved in psychomotor development. The use of cognitive visualization has not been examined in vascular anastomosis in a randomized trial setting. The objective of this study was to examine the effect of visualization of surgical steps via instructional media on performance of an end-to-side microvascular anastomosis during simulation.

\section{METHODS}

\section{Study Population}

All subjects recruited to this study were first- and second-year surgical trainees of all subspecialties at the University of Ottawa tertiary care hospital system based in Ottawa, Canada. Subjects were excluded if they had previously participated in an expert-guided teaching session on vascular anastomosis, used the bench model, or had previously completed residency training.

\section{Study Design}

This was a single-center, single-blinded randomized control trial run at the University of Ottawa Skills and Simulation Center (Appendix E1). The study was approved by the Ottawa Hospital Research Ethics Board, and all subjects provided consent to participate. The study protocol adhered to the consolidated standards of reporting trials under the Consolidated Standards

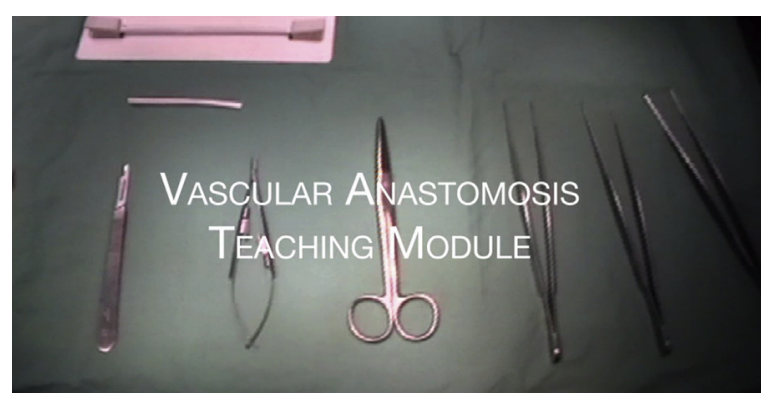

VIDEO 1. Video illustrating the use of visualization techniques to teach vascular anastomosis. Video available at: http://www.jtcvsonline.org/ article/S0022-5223(17)32414-5/fulltext.

of Reporting Trials Statement. Between September 2013 and April 2014, a total of 32 surgical trainees were recruited.

A commercially available procedural trainer (Limbs \& Things, Savannah, Ga) was used to simulate an end-to-side anastomosis (Figure 1). Nonringed, 4-mm polytetrafluoroethylene grafts (W. L. Gore \& Associates, Inc, Flagstaff, Ariz) were sutured with a 5-0 polypropylene suture (Covidien AG, Mansfield, Mass) in a running fashion with microvascular surgical instruments.

All subjects received an initial didactic session involving a comprehensive overview of the technical steps and principles of performing an end-toside microvascular anastomosis (Figure 2). Next, subjects independently performed one anastomosis on the procedural trainer. This "pretest" established subject baseline surgical skills, and subjects were informed they were going to be videotaped and scored. Videotaping focused only on performance of anastomosis on the bench model and did not include subject names or faces to avoid identification of the subject. Subsequently, subjects were given the opportunity to perform 2 anastomoses under the expert guidance of cardiac and vascular surgeons in a one-to-one teaching strategy using a consensus-determined standardized teaching strategy. No magnifying loops were used in the study by any subject.

Subjects were then randomized to either intervention (those who received the supplementary instructional multimedia to use independently) or control arms. Computer-generated randomization was performed with stratification based on postgraduate year (PGY) of training (PGY1 and PGY2). The intervention was a professionally made, high-definition video illustrating the use of visualization in describing all important steps, anatomical landmarks, and pitfalls involved in performing vascular anastomosis (Video 1). The video divided the procedure into a logical flow of steps to facilitate visualization of the procedure as a mental task. This video was password-protected and conveniently accessible on iPads, tablets,

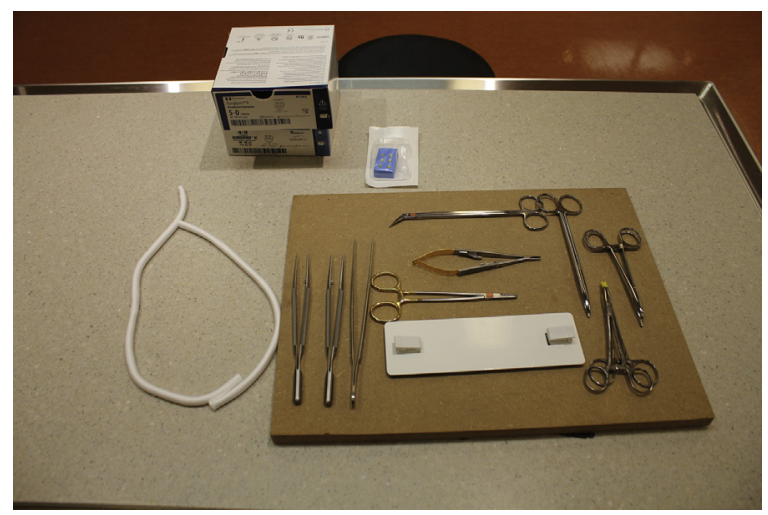

FIGURE 1. Bench model for vascular anastomosis, involving 4-mm polytetrafluorene grafts, Prolene suture, and microvascular equipment. 


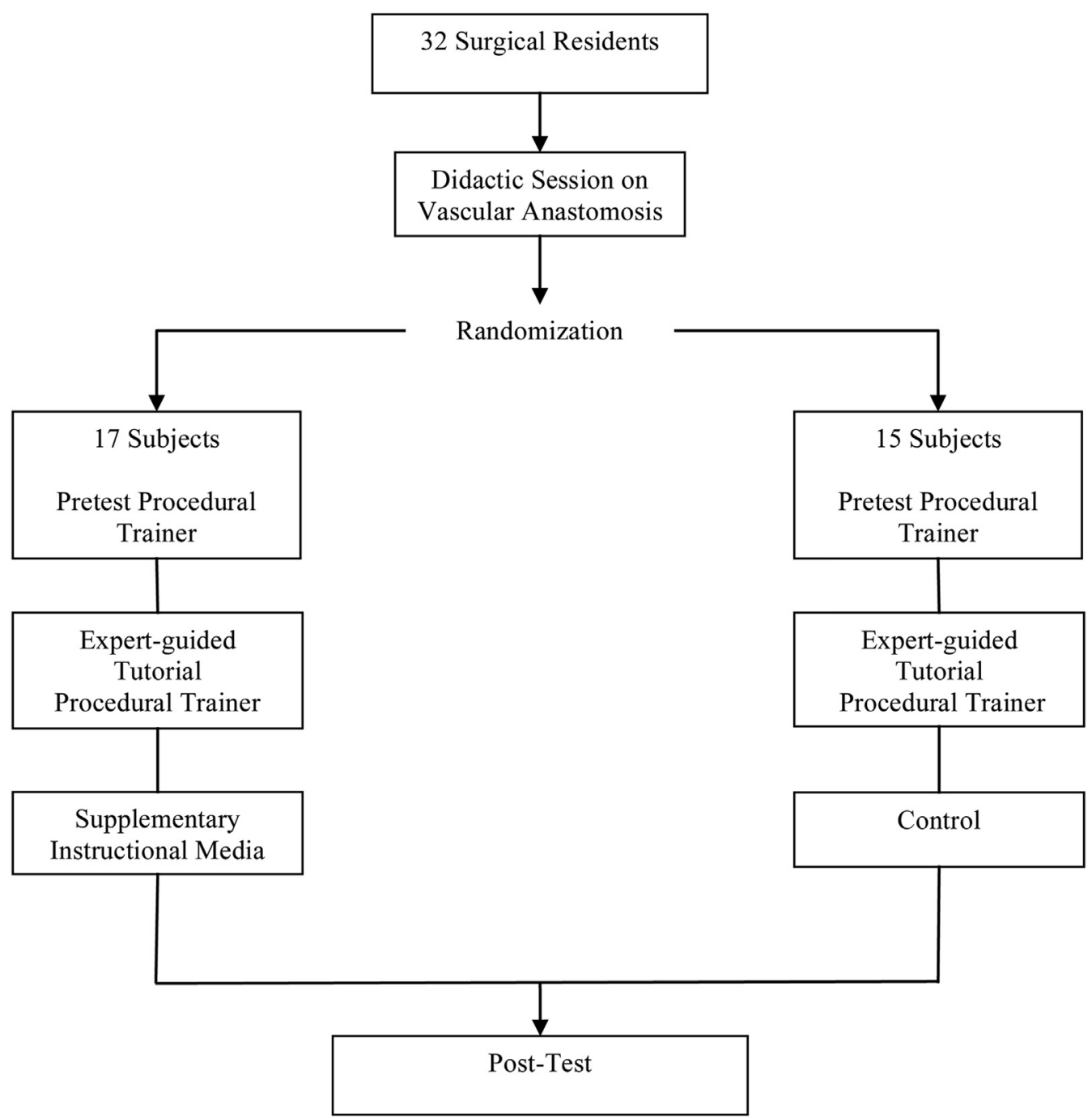

FIGURE 2. Schematic illustrating study design and randomization process.

computers, etc. Contrary to the control group, the "intervention" subjects were instructed to watch the video a total of 5 times. All subjects returned after a period of 1 week to perform the "posttest" anastomosis on the same procedural model under the same conditions with videotaping.

\section{Study Endpoints}

Participants were videotaped and scored in both pretest and posttest performances by 2 expert observers. These raters were 2 expert cardiac surgeons who were blinded to the category of randomization and identity of participants and phase of testing. Both raters were trained in the use of both Objective Structured Assessment of Technical Skill (OSATS) and the End-Product Rating Score (EPRS), including appropriate use of the entire scale and common interpretation of the anchors provided to guide scoring. Further calibration was achieved by rating of pilot performance jointly, followed by discussion and convergence on significant differences. An intraclass correlation was used to assess the interrater reliability across study participants. Recording was limited to subject's hands only and coded anonymously, with no identifying information available. Scoring was performed with the use of 3 validated measures in vascular anastomosis: the OSATS score, EPRS, and total time to completion.

The primary endpoint used for assessing technical proficiency was the OSATS score, developed at the University of Toronto (Table 1). Although used as a general global rating of surgical skill, ratings on the OSATS have been validated for assessment of technical skills in surgical residents. ${ }^{9-11}$ Furthermore, the OSATS has been used extensively to score performance of vascular anastomosis ${ }^{4,12,13}$ and has demonstrated excellent transferability of skill from bench model to the operating theater. ${ }^{14}$ A modified version of the OSATS was used in this study, with 5 categories marked on a Likert scale from 1 to 5 (tied with descriptive anchors) for a total of 25 points. Secondary endpoints for assessment include the EPRS and time to completion. The EPRS is a 5-point Likert global rating scale that assesses 4 important parameters of skill: suture spacing, suture eversion, quality of the heel of the anastomosis, and quality of the anastomotic toe ${ }^{15}$ (Table 2). Finally, although time to completion is a crude indicator of technical skill, an increase in experience speed signifies economy of movement instead of haste ${ }^{16}$; time to completion has been used extensively as another assessment tool of surgical skill. ${ }^{4,8,15-17}$

\section{Statistical Analysis}

Baseline data are reported with means and standard deviations for continuous variables and numbers and percentages for categorical variables. Means of continuous variables were compared via a 2-tailed Student $t$ test. Categorical variables were compared with the $\chi^{2}$ test or Fisher exact test as appropriate. STATA/SE 13.1 (StataCorp LP, College Station, Tex) was used to perform statistical calculations. 
TABLE 1. Modified Objective Structured Assessment of Technical Skills (OSATS) score

\begin{tabular}{|c|c|c|c|c|c|}
\hline Time and motion & $\begin{array}{c}1 \\
\text { Many unnecessary moves }\end{array}$ & 2 & $\begin{array}{l}3 \\
\text { Efficient time/motion, but some } \\
\text { unnecessary moves }\end{array}$ & 4 & $\begin{array}{l}5 \\
\text { Clear economy of movement and } \\
\text { maximum efficiency }\end{array}$ \\
\hline Instrument handling & $\begin{array}{l}1 \\
\text { Repeatedly makes tentative or } \\
\text { awkward moves with instruments } \\
\text { by inappropriate use of } \\
\text { instruments }\end{array}$ & 2 & $\begin{array}{l}3 \\
\text { Competent use of instruments but } \\
\text { occasionally appeared stiff or } \\
\text { awkward }\end{array}$ & 4 & $\begin{array}{l}5 \\
\text { Fluid moves with instruments and } \\
\text { no awkward moves }\end{array}$ \\
\hline Flow of operation & $\begin{array}{l}1 \\
\text { Frequently stopped operating and } \\
\text { seemed unsure of next move }\end{array}$ & 2 & $\begin{array}{c}3 \\
\text { Demonstrated some forward } \\
\text { planning with reasonable } \\
\text { progression of procedure }\end{array}$ & 4 & $\begin{array}{l}5 \\
\text { Obviously planned course of } \\
\text { operation with effortless flow } \\
\text { from one move to the next }\end{array}$ \\
\hline Use of assistants & $\begin{array}{l}1 \\
\text { Consistently placed assistants } \\
\text { poorly or failed to use assistants }\end{array}$ & 2 & $\begin{array}{l}\text { Appropriate use of assistants most } \\
\text { of the time }\end{array}$ & 4 & $\begin{array}{l}5 \\
\text { Strategically used assistants to the } \\
\text { best advantage at all times }\end{array}$ \\
\hline $\begin{array}{l}\text { Knowledge of specific } \\
\text { procedure }\end{array}$ & $\begin{array}{l}1 \\
\text { Deficient knowledge: needed } \\
\text { specific instruction at most steps }\end{array}$ & 2 & $\begin{array}{l}\text { 3 } \\
\text { Knew all important steps of the } \\
\text { operation }\end{array}$ & 4 & $\begin{array}{l}5 \\
\text { Demonstrated familiarity with all } \\
\text { steps of the operation }\end{array}$ \\
\hline
\end{tabular}

Comparison of means within groups for each measure (OSATS, ERPS, time) was calculated via a paired $t$ test. Comparison of means between groups was performed with the analysis of covariance model. Posttest parameters were compared between groups after adjustment for pretest parameters as a covariate in the model. The advantage of this approach is that it controls for any a priori differences in performance between participants assigned to the control or intervention group. The intraclass correlation coefficient was used to calculate interrater reliability between the expert raters via a 2-way randomeffects model.

Sample size was calculated with a standardized effect size of 1.0. Given the large costs associated with the study teaching modality, we selected a standardized effect size of 1 because it is considered large in medical education literature and is often used in similar studies. ${ }^{4,18-22}$ With 16 subjects in each group, using a $\beta$ of 0.20 and a 2-tailed $\alpha$ of 0.05 , we had $80 \%$ power to detect a standardized effect size of 1.0 .

\section{RESULTS}

Baseline demographics for all participants are illustrated in Table 3. The proportion of PGY1 to PGY2 level trainees in both groups was similar. There was no attrition throughout the study and no crossover between randomization groups. Follow-up was $100 \%$ complete for all participants. The group of subjects in the intervention arm watched the video more than the minimum number of times instructed, as verified by a video tracking counter. Pretest scores were similar between intervention versus control groups for both OSATS $(8.7 \pm 2.5$ vs $7.8 \pm 2.0, P=.27)$ and EPRS (5.29 \pm 1.4 vs $4.73 \pm 0.8, P=.19)$. However, time to completion was longer for the intervention group compared with the control group $(19.1 \pm 1.0$ minutes vs $17.0 \pm 3.2$ minutes, $P=.03$ ).

In subjects who used visualization multimedia, OSATS and EPRS scores significantly improved between pre- and posttests, respectively $(8.71 \pm 2.52$ vs $17.41 \pm 2.92$, $P<.001)$ and $(5.29 \pm 1.49$ vs $11.24 \pm 3.03, P<.001)$. Total time to perform the anastomosis significantly decreased $(19.13 \pm 1.06$ minutes vs $15.75 \pm 3.00$ minutes, $P<.001)$. In a similar fashion, OSATS and EPRS scores improved substantially between pre- and posttests in the control group $(7.80 \pm 2.04$ vs $14.27 \pm 3.20, P<.001$ and $4.73 \pm 0.80$ vs $7.40 \pm 4.14, P=.027)$. Total time was also significantly smaller in this group $(17.02 \pm 3.21 \mathrm{mi}-$ nutes vs $14.28 \pm 3.35$ minutes, $P=.003$ ).

After we accounted for baseline pretest values as a covariate, comparison of posttest OSATS and EPRS scores for

TABLE 2. End Product Rating Score (EPRS)

\begin{tabular}{|c|c|c|c|c|c|}
\hline Suture spacing & $\begin{array}{c}1 \\
\text { Bites inconsistent in size and } \\
\text { depth, with wide gaps }\end{array}$ & 2 & 3 & 4 & $\begin{array}{c}5 \\
\text { Consistently equal and } \\
\text { appropriate spacing }\end{array}$ \\
\hline Suture eversion & $\begin{array}{c}1 \\
\text { Inadequate }\end{array}$ & 2 & 3 & 4 & $\begin{array}{c}5 \\
\text { Superior performance }\end{array}$ \\
\hline Quality of anastomotic heel & $\begin{array}{c}1 \\
\text { Inadequate }\end{array}$ & 2 & 3 & 4 & $\begin{array}{c}5 \\
\text { Superior performance }\end{array}$ \\
\hline Quality of anastomotic toe & $\begin{array}{c}1 \\
\text { Inadequate }\end{array}$ & 2 & 3 & 4 & $\begin{array}{c}5 \\
\text { Superior performance }\end{array}$ \\
\hline
\end{tabular}


TABLE 3. Baseline demographics of all subjects

\begin{tabular}{lccl}
\hline & $\begin{array}{c}\text { Intervention } \\
(\mathbf{n}=\mathbf{1 7})\end{array}$ & $\begin{array}{c}\text { Control } \\
(\mathbf{n}=\mathbf{1 5})\end{array}$ & $\boldsymbol{P}$ value \\
\hline PGY 1 & $9(52.9 \%)$ & $8(53.3 \%)$ & 1.0 \\
Subspecialty & & & \\
$\quad$ General surgery & $5(29.4 \%)$ & $5(33.3 \%)$ & \\
Orthopedics surgery & $1(5.8 \%)$ & $3(20 \%)$ & \\
Urology & $3(17.6 \%)$ & $1(6.7 \%)$ & \\
Cardiac surgery & $1(5.8 \%)$ & 0 & \\
Vascular surgery & $2(11.7 \%)$ & 0 & \\
Obstetrics and gynecology & $1(5.8 \%)$ & $2(13.4 \%)$ & \\
Plastic surgery & 0 & $3(20 \%)$ & \\
Neurosurgery & $2(11.7 \%)$ & 0 & \\
\hline
\end{tabular}

$P G Y$, Postgraduate year.

the control and intervention groups demonstrated a significant difference. We found that both OSATS and EPRS scores increased to a greater degree for trainees randomized to usage of visualization multimedia, with $P=.013$ for OSATS and $P=.011$ for EPRS. However, there was a nonsignificant effect of group on time to completion, with the mean of the control group not differing from that of the intervention group (14.27 \pm 3.20 minutes vs $15.75 \pm 3.00$ minutes, $P=.79$ ). These results are illustrated in Figure 3. The intraclass correlation between raters was 0.90 .

Although the study was not powered to assess performance differences across PGY level, we sought to evaluate trends by assessing the data groups separately. When preand postperformance scores were analyzed separately, PGY1 trainees had trends toward greater OSATS $(8.53 \pm 2.3$ vs $16.5 \pm 3.1, P=.225)$ and EPRS scores $(4.82 \pm 1.1$ vs $9.29 \pm 3.9, P=.63)$. In contrast, PGY2 trainees had greater OSATS $(8 \pm 2.3$ vs $15.3 \pm 3.7$, $P=.011)$ and EPRS scores $(5.27 \pm 1.3$ vs $9.6 \pm 4.3$, $P=.001)$. Although performance speed increased, there was no difference at both levels (PGY1 $18.9 \pm 1.6$ vs $15.4 \pm 2.8$ minutes, $P=.86 ;$ PGY2 $17.3 \pm 3.1$ vs $14.7 \pm 3.7$ minutes, $P=.63$ ).

\section{DISCUSSION}

With the current limitations to trainee operative experience and concerns for patient safety, it is not surprising that surgical simulation training has secured a crucial role in training curricula as an alternative educational tool. Consequently, with emerging technologies, simulation centers have proliferated worldwide to enhance teaching of technical skills in a nonclinical setting. This array of instructional tools, both high- and low-fidelity models, has been validated as effective teaching tools in multiple domains. ${ }^{7}$ Simulation permits practicing skills in a lowstress, patient-safe environment, leaving room for errors and learning from consequences without impact on patient safety.
Although simulation is an appealing alternative to bridging the gap in surgical experience, certain limitations exist that have important implications on the learning process. Kopta outlined his theory of learning technical skills into 3 major steps: cognitive, integrative, and autonomous stages. ${ }^{23}$ The cognitive phase involves intellectualizing a task into component steps via visualization. In a similar fashion, multiple learning theories distinguish between the cognitive aspects of learning and the mechanical psychomotor skills involved in learning a procedure. One of the shortcomings of simulation training is its emphasis on physical dexterity and motor skill development over that of cognitive training. However, task-learning requires mastery of both physical dexterity and cognitive visualization, which allows for a more complete understanding and recognition of important lines of dissection, anatomical patterns and cues, and pitfalls during a procedure. Unfortunately, sufficiently realistic simulation models that adequately replicate the true anatomy with these dynamic features are lacking; this type of learning is generally limited to photographic images from academic texts and from true operative exposure. ${ }^{24}$ Although cadaveric or animal models and virtual reality are helpful for learning, they can be costly and problematic from an ethical perspective. Virtual reality is not sufficiently developed to fully simulate an identical environment and incorporate subtle perceptual cues of the true anatomy and tactile feedback. ${ }^{24}$

This randomized clinical trial suggests that performance outcomes can be influenced with the use of visualization as a teaching strategy. Although simulation training alone resulted in significant improvements, the use of visualization multimedia resulted in greater improvement above and beyond that of simulation alone in both technical performance and final end product. However, the mean time to completion of the anastomosis was similar between both arms. This is an expected result, suggesting that visualization addresses the cognitive features over the mechanical motor skills involved with practice. The study was designed to mirror realistic surgical residency simulation training. It is important to note that the additional visualization video did not contain any new information not already delivered in the initial didactic lecture. It was designed to summarize the important steps, anatomical landmarks, and pitfalls of vascular anastomosis using the method of visualization. Although one can speculate that the additional material review may affect the positive outcome, the impact of additional types of review on this effect will be the focus of future studies.

Interestingly, when data were assessed separately by PGY level, we observed a larger improvement in OSATS and EPRS at the PGY2 level compared with PGY1. Although we do not have enough power to form definitive conclusions, we speculate that one possible explanation 


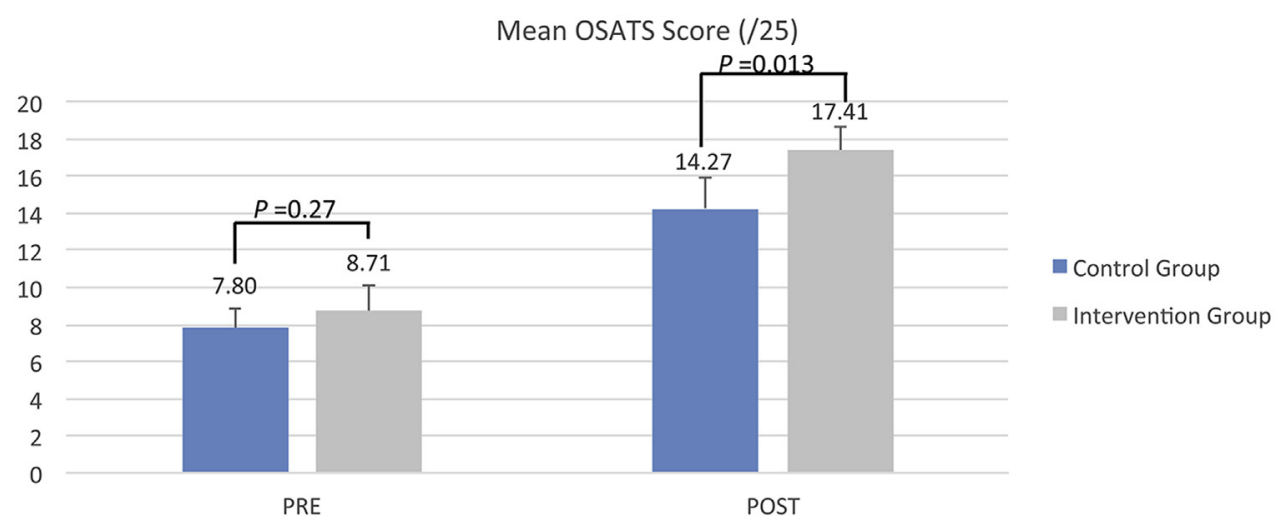

A

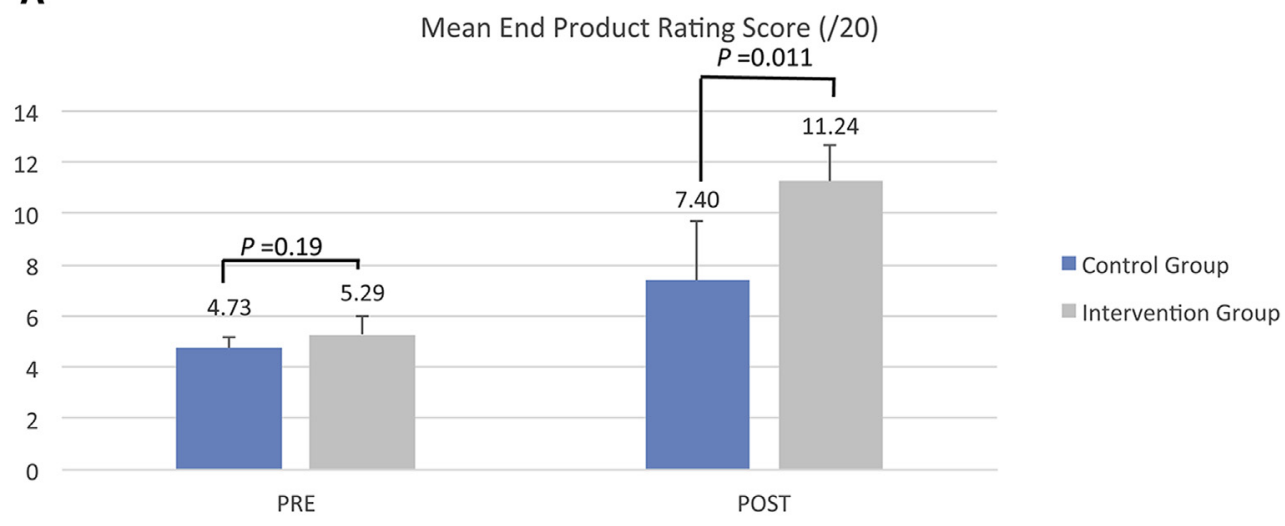

B

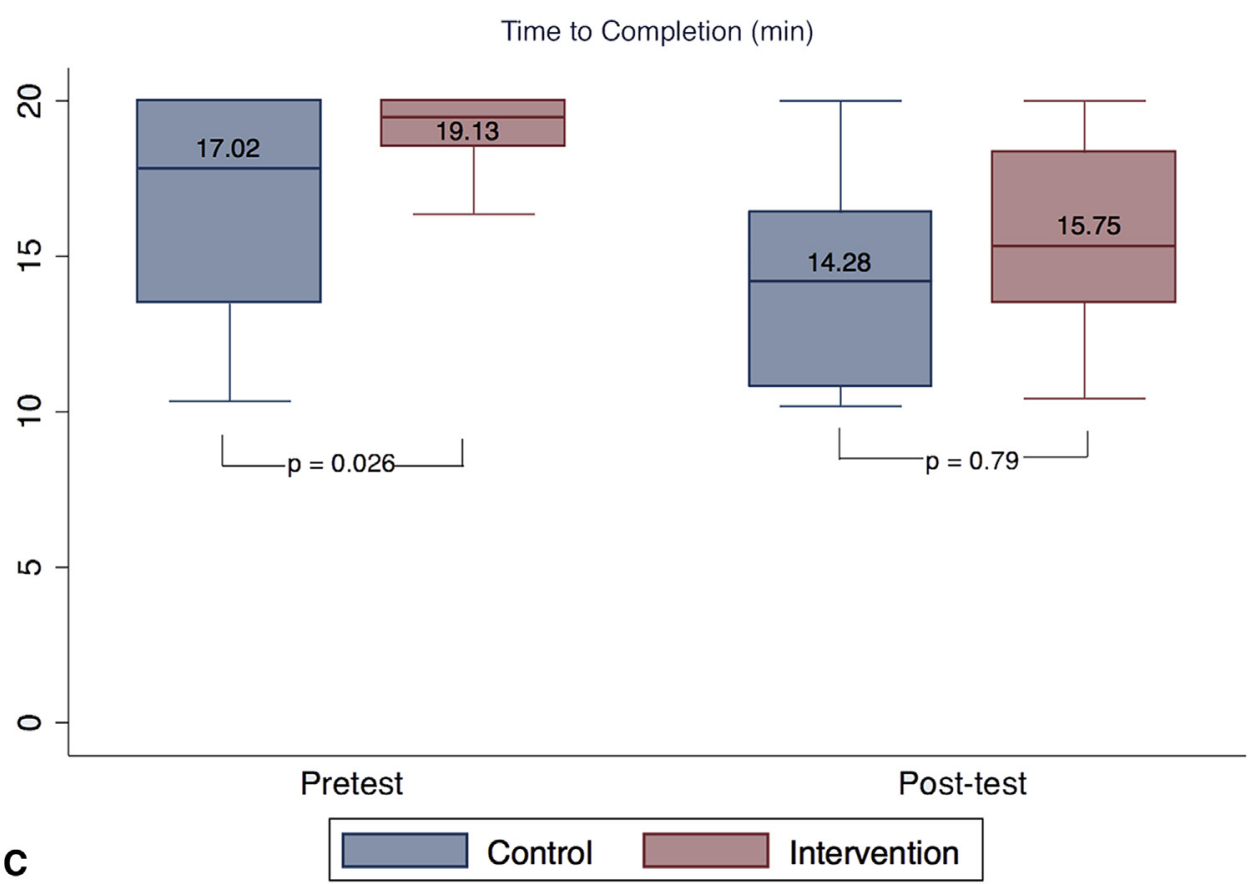

FIGURE 3. A, OSATS scores for intervention and control groups. B, End Product Rating Scores for intervention and control groups. C, Mean time to completion for intervention and control groups. Number of subjects: intervention, $\mathrm{n}=17$; control, $\mathrm{n}=15$. OSATS, Objective Structured Assessment of Technical Skill. 
for this heightened effect in higher-level students may be due to a more developed surgical skillset and a greater ability to benefit from repeated exposure to visualization of vascular anastomosis, which is considered a relatively complex procedure. Of note, subgroup analysis in this small sample size may mask the ability to detect a statistically significant improvement in either group.

\section{CONCLUSIONS}

The results from this study have important implications on surgical education. Emphasis should be placed on all aspects of psychomotor development-motor and cognitive-to enhance the learning curve of a procedure. This is particularly important in a critical procedure like vascular anastomosis, where the quality of anastomosis has a direct impact on life expectancy of the graft and on patient outcomes. In effect, we must continue to develop and refine surgical education to include new methods of teaching such as visualization. The production of visualization multimedia to enhance teaching is effective, inexpensive, and easy to disseminate to surgical trainees. This can be incorporated with simulation with the inexpensive, low-fidelity bench model to improve surgical skill development. Previous studies have demonstrated that independent practice on low-fidelity models do translate into improvements in performance in operating room live environments. ${ }^{4,14}$ Furthermore, a recent systematic review of 24 multidisciplinary studies suggests that super technical performance, as assessed by a variety of parameters such as intraoperative technical scores and postoperative evaluation of imaging, positively affected patient performance and outcomes. ${ }^{25}$ As we approach the era of competency-based training, the importance of effective technique and training strategies cannot be overemphasized.

\section{Limitations}

One of the major limitations is that the results may not be generalizable to more experienced trainees ( $>$ PGY 3) due to our restriction of the study population to only firstand second-year trainees only. However, we believe that a ceiling effect will likely predominate in trainees with higher level of training. Also, although trainees in the intervention arm have reported watching the multimedia video, the possibility of misclassification bias exists if this was not the case. Even though we have tracked the total number of times the video was watched, we have no way of tracking this to individual subjects. This can result in bias toward the null in assessment of efficacy of the intervention.

One other limitation to this study is the use of polytetrafluoroethylene grafts to simulate human coronary anastomosis, which entails a smaller graft and target vessel size compared with that used in the current simulation scheme. Furthermore, the blinding process could be further refined by mandating the use of surgical gloves for all subjects in the protocol, which would also improve generalizability to a real operating room setting. Although randomization placed 3 more cardiac or vascular trainees in the intervention arm by chance, this is unlikely to bias results, particularly that these were PGY 1 trainees with little experience in a complex skill like vascular anastomosis and pretest scores were similar between groups.

Another limitation in the study is the uncertainty in the link between OSATS/EPRS scores and clinical outcomes. As discussed previously, there are limited data that positively link technical performance scores to improved clinical outcomes, but this necessitates further studies to elucidate these effects. Furthermore, although these technical scores are valuable assets in the evaluation of trainee performance and progress, they are only stepping stones in the larger path of competency training.

\section{Future Directions}

The results from this study on the efficacy of visualization as a teaching modality have important implications on surgical curricula. Our goal is to expand this modality to other procedures within the field of cardiovascular surgery and to other surgical specialties. Furthermore, although we found a significant difference in efficacy after a week, we do not know the retention of skill in the short and long term. A second step would involve performing a test to assess for retention of skill at different time frames and to assess different forms of review.

\section{Conflict of Interest Statement}

Authors have nothing to disclose with regard to commercial support.

The authors give special thanks to Ms Christine Seabrook, Surgical Coordinator, and the staff at the University of Ottawa Skills $\&$ Simulation Center. The authors also thank Dr Marcia Testa, Harvard School of Public Health, for her guidance and assistance in this study and Timothy Wood from the University of Ottawa.

\section{References}

1. Robinson WP, Baril DT, Taha O, Schanzer A, Larkin AC, Bismuth J, et al. Simulation-based training to teach open abdominal aortic aneurysm repair to surgical residents requires dedicated faculty instruction. J Vasc Surg. 2013;58: 247-53. e1-2.

2. Connors RC, Doty JR, Bull DA, May HT, Fullerton DA, Robbins RC. Effect of work-hour restriction on operative experience in cardiothoracic surgical residency training. J Thorac Cardiovasc Surg. 2009;137:710-3.

3. Watson DR, Flesher TD, Ruiz O, Chung JS. Impact of the 80-hour workweek on surgical case exposure within a general surgery residency program. J Surg Educ. 2010;67:283-9.

4. Price J, Naik V, Boodhwani M, Brandys T, Hendry P, Lam B-K. A randomized evaluation of simulation training on performance of vascular anastomosis on a high-fidelity in vivo model: The role of deliberate practice. J Thorac Cardiovasc Surg. 2011;142:496-503.

5. Bismuth J, Donovan MA, O'Malley MK, El Sayed HF, Naoum JJ, Peden EK, et al. Incorporating simulation in vascular surgery education. J Vasc Surg. 2010;52:1072-80. 
6. Reznick RK, MacRae H. Teaching surgical skills—changes in the wind. $N$ Engl J Med. 2006;355:2664-9.

7. Moulton CA, Dubrowski A, MacRae H, Graham B, Grober E, Reznick R. Teaching surgical skills: what kind of practice makes Perfect? A randomized, controlled trial. Ann Surg. 2006;244:400-9.

8. Fann JI, Caffarelli AD, Georgette G, Howard SK, Gaba DM, Youngblood P, et al. Improvement in coronary anastomosis with cardiac surgery simulation. J Thorac Cardiovasc Surg. 2008;136:1486-91.

9. Faulkner H, Regehr G, Martin J, Reznick R. Validation of an objective structured assessment of technical skill for surgical residents. Acad Med. 1996; 71:1363-5

10. Martin JA, Regehr G, Reznick R, MacRae H, Murnaghan J, Hutchison C, et al. Objective structured assessment of technical skill (OSATS) for surgical residents. Br J Surg. 1997;84:273-8.

11. Reznick R, Regehr G, MacRae H, Martin J, McCulloch W. Testing technical skill via an innovative "bench station" examination. Am J Surg. 1997;173: 226-30.

12. Sidhu RS, Chen J, Baxter K, Wu H. Development of a comprehensive vascular skills assessment for surgical trainees. Am J Surg. 2009; 197:591-4; discussion 594.

13. Pandey VA, Wolfe JHN, Lindahl AK, Rauwerda JA, Bergqvist D. Validity of an exam assessment in surgical skill: EBSQ-VASC Pilot Study. Eur J Vasc Endovasc Surg. 2004;27:341-8.

14. Anastakis DJ, Regehr G, Reznick RK, Cusimano M, Murnaghan J, Brown M, et al. Assessment of technical skills transfer from the bench training model to the human model. Am J Surg. 1999;177:167-70.

15. Datta V, Mandalia M, Mackay S, Chang A, Cheshire N, Darzi A. Relationship between skill and outcome in the laboratory-based model. Surgery. 2002;131: 318-23.

16. Pandey VA, Black SA, Lazaris AM, Allenberg JR, Eckstein HH, Hagmuller GW, et al. Do workshops improved the technical skill of vascular surgical trainees? Eur J Vasc Endovasc Surg. 2005;30:441-7.
17. Backstein D, Agnidis Z, Sadhu R, MacRae H. Effectiveness of repeated video feedback in the acquisition of a surgical technical skill. Can J Surg. 2005;48: 195-200.

18. Torgerson DJ, Torgerson CJ. Designing Randomised Trials in Health, Education and the Social Sciences: An Introduction. New York: Palgrave Macmillan UK; 2008.

19. Leppink J, O'Sullivan P, Winston K. Effect size—-large, medium, and small. Perspect Med Educ. 2016;5:347-9.

20. Lipsey MW, Puzio K, Yun C, Hebert MA, Steinka-Fry K, Cole MW, et al. Trans lating the Statistical Representation of the Effects of Education Interventions Into More Readily Interpretable Forms. Washington, DC: National Center for Special Education Research, Institute of Education Sciences; 2012.

21. Matsumoto ED, Hamstra SJ, Radomski SB, Cusimano MD. The effect of bench model fidelity on endourological skills: a randomized controlled study. J Urol. 2002;167:1243-7.

22. Cohen J. Statistical Power Analysis for the Behavioral Sciences. Hillsdale, NJ: L. Erlbaum Associates; 1988.

23. Wanzel KR, Ward M, Reznick RK. Teaching the surgical craft: from selection to certification. Curr Probl Surg. 2002;39:573-659.

24. Guerlain S, Kristen Brook G, LaFollette M, Mersch TC, Mitchell BA, Poole GR, et al. Improving surgical pattern recognition through repetitive viewing of video clips. IEEE Trans Syste Man Cybern A. 2004;34:699-707.

25. Fecso AB, Szasz P, Kerezov G, Grantcharov TP. The effect of technical performance on patient outcomes in surgery: a systematic review. Ann Surg. 2017; 265:492-501.

Key Words: anastamosis, surgical/education, clinical competence, microsurgery/education, vascular surgical procedures/education, teaching/methods, single blind randomized control trial 


\section{APPENDIX E1. PROJECT PROTOCOL}

Our study is a randomized control trial in which surgical residents, selected from the University of Ottawa surgical training programs (postgraduate years 1 and 2 only), will be recruited to learn about vascular anastomosis. All sessions will occur at the University of Ottawa Skills \& Simulation Center on the Civic Campus.

\section{Session 1 \\ Didactic teaching session. All trainees will attend a didac- tic training session consisting of a review of all technical steps and principles of vascular anastomosis. Instructors of these sessions are expert cardiac or vascular surgeons who will provide guidance to trainees. This teaching session will include a PowerPoint presentation with images and in- structions on how to complete an end-to-side vascular anas-} tomosis ( $\sim 15$ minutes in length).

Pretest. After the didactic teaching session, students will undergo a "pretest," where they will complete a single vascular anastomosis on a commercially available practice bench model to perform a single end-to-side anastomosis using segments of 4-mm diameter rubber tubing, standard surgical sutures, and instruments. This pretest will be recorded via video camera for grading by experts using multiple grading criteria. This establishes baseline surgical skills of the trainees ( $\sim 20$ minutes).

Simulation training. After the pretest, trainees will have the opportunity to practice on these bench models to perform end-to-side anastomosis with 5-0 polypropylene sutures in running fashion. Trainees will be instructed to perform a total 2 anastomoses under guidance and observation by an expert. Trainees will have a maximum amount of time for completing both anastomoses at 30 minutes. This parallels current training paradigms, where a surgeon will be available to provide teaching for a surgical skill.

Randomization. Trainees will then be randomized to 2 groups:

Group 1: supplementation with instructional media. This group will be provided with instructional media consisting of an animated video with instructional media to assist them with visualization of all steps necessary to complete the procedure. This material contains the same information that was covered in the initial didactic session. Trainees will be instructed to review the instructional multimedia as many times as they please (a minimum of 5 times) over a period of 1 week. They will log the number of times and dates of when they watched the video and submit their $\log$.
Group 2: no supplementation of instructional media. This group will not be provided with the instructional media after the initial didactic session. The participants are simply instructed to return to the Simulation center after 1 week.

\section{Session 2}

Both groups will return after a period of 1 week to complete a posttest, or a chance to complete a vascular anastomosis in a simulated environment. This will be recorded via video camera as well for grading by experts.

This session only comprises completion of the same vascular end-to-side anastomosis on the same exact bench model. There will be no teaching during this session. Students will only perform the single vascular anastomosis with a time limit of 20 minutes.

Residents will be scored in the same way in each session; all anastomoses will be recorded and graded by blinded expert observers. Trainees will also be informed that they will be timed and graded.

NOTE: Objective scoring of technical skills will be based on 3 methods:

1. Time to completion of task:

Trainees will begin the anastomosis from a standardized position. The length of time recorded will be from the start until after tying the final knot. There will be a maximum of 20 minutes to complete an anastomosis.

2. Objective Structured Assessment of Technical Skill (OSATS) global ratings scale:

The OSATS is a scale that grades 7 distinct fields each from 1 to 5 points, totaling to 35 points for an overall score.

3. End-Product Rating Score:

The end product will be graded on a 4-parameter global rating scale by blinded observers. These parameters are suture spacing, suture eversion, quality of the heel of the anastomosis, and the quality of the anastomotic toe. Each category will be graded 1 to 5 , with the total mark out of 20 .

Nota Bene: The OSATS score from the University of Toronto has been used extensively and validated as a measure of technical skill. The OSATS score and the time to completion are considered measures of generic surgical skill. Quality of the anastomosis will be evaluated using the End-Product Rating Score, which correlates well with manual dexterity. 

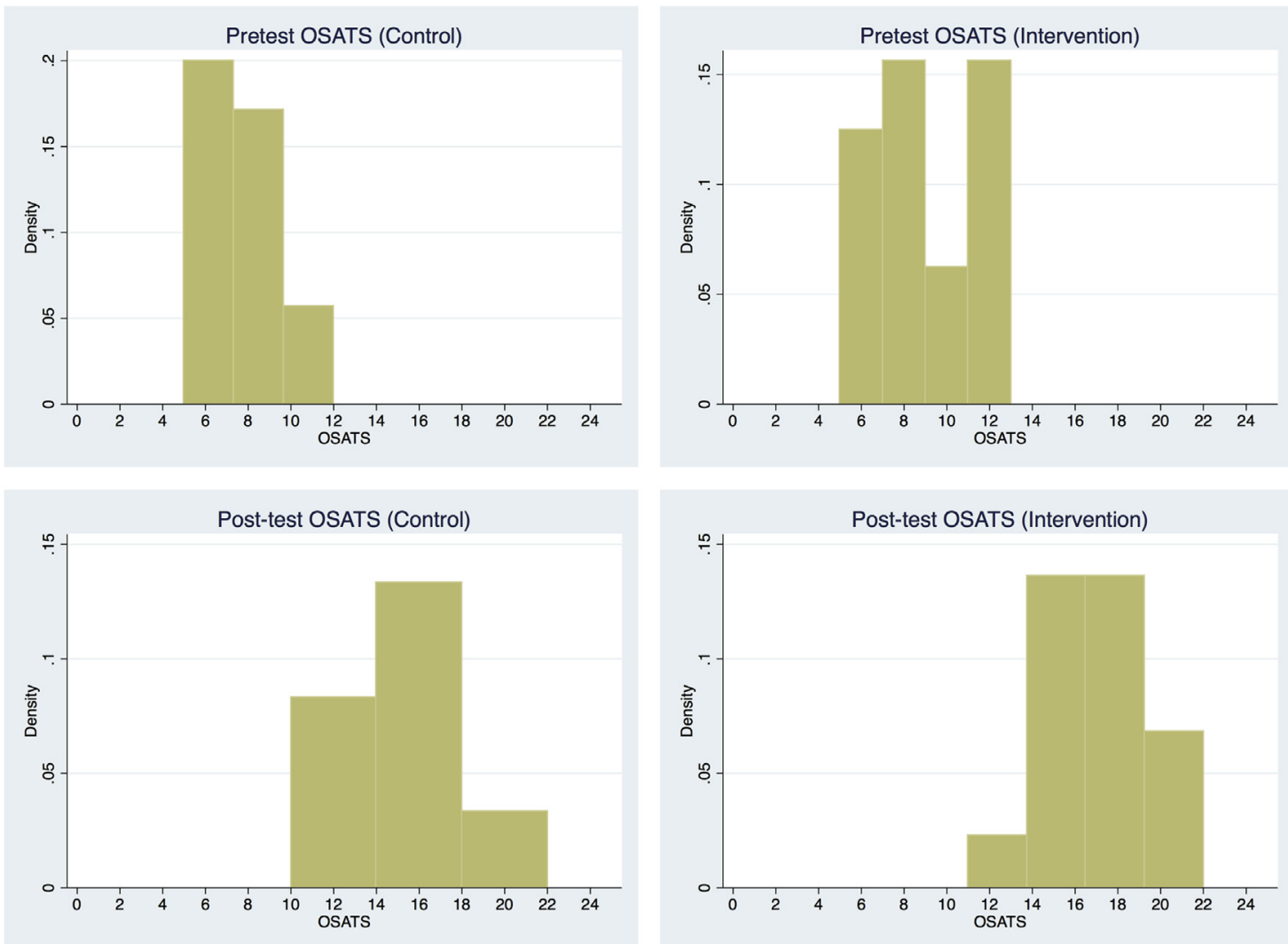

FIGURE E1. Pretest (upper panel) and post-test (lower panel) OSATS histograms (control vs intervention). Total number of subjects, $\mathrm{n}=32$. OSATS, Objective Structured Assessment of Technical Skill. 

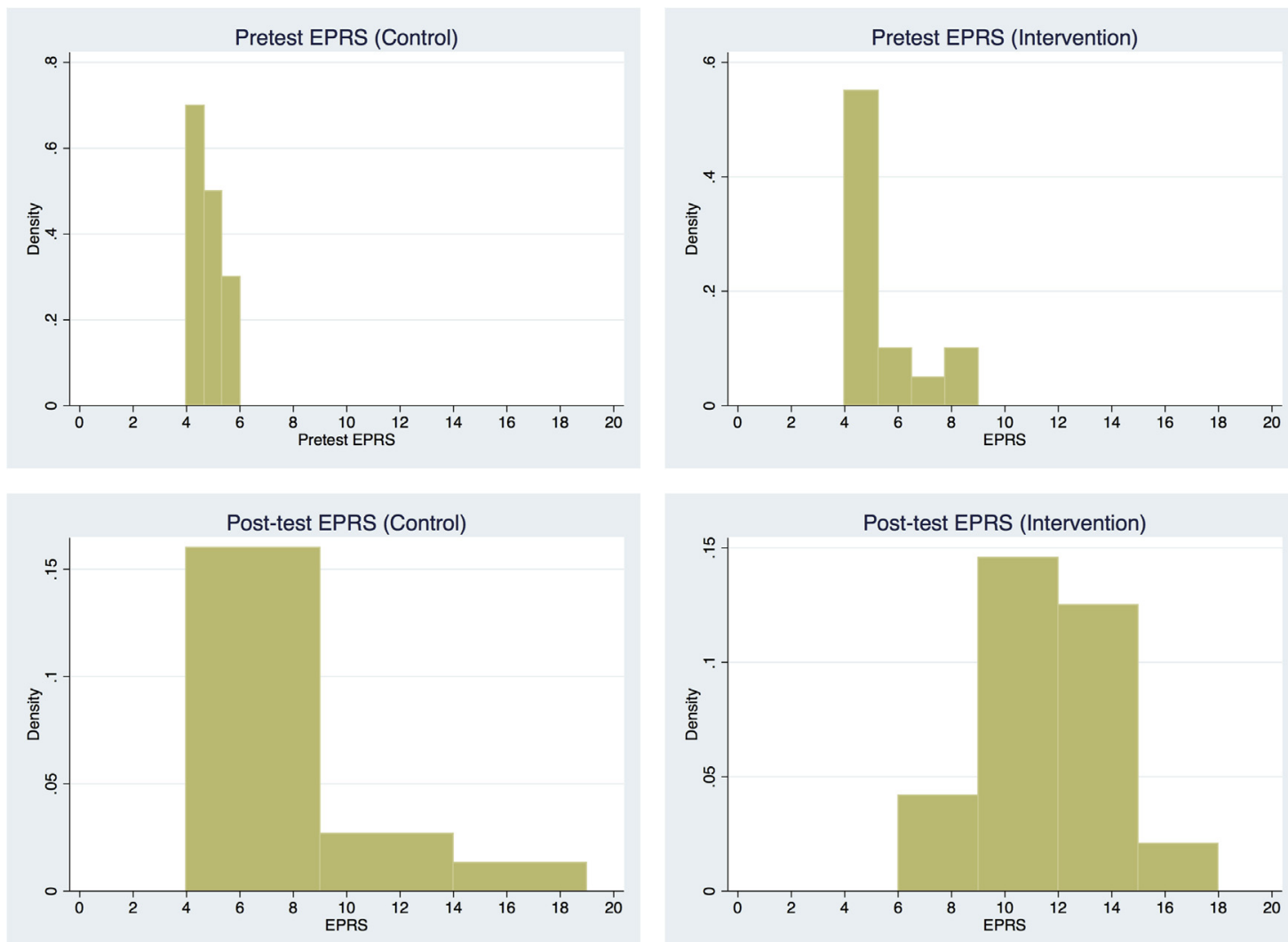

FIGURE E2. Pretest (upper panel) and post-test (lower panel) EPRS histograms (control vs intervention). Total number of subjects, $\mathrm{n}=32$. EPRS, End-Product Rating Score. 

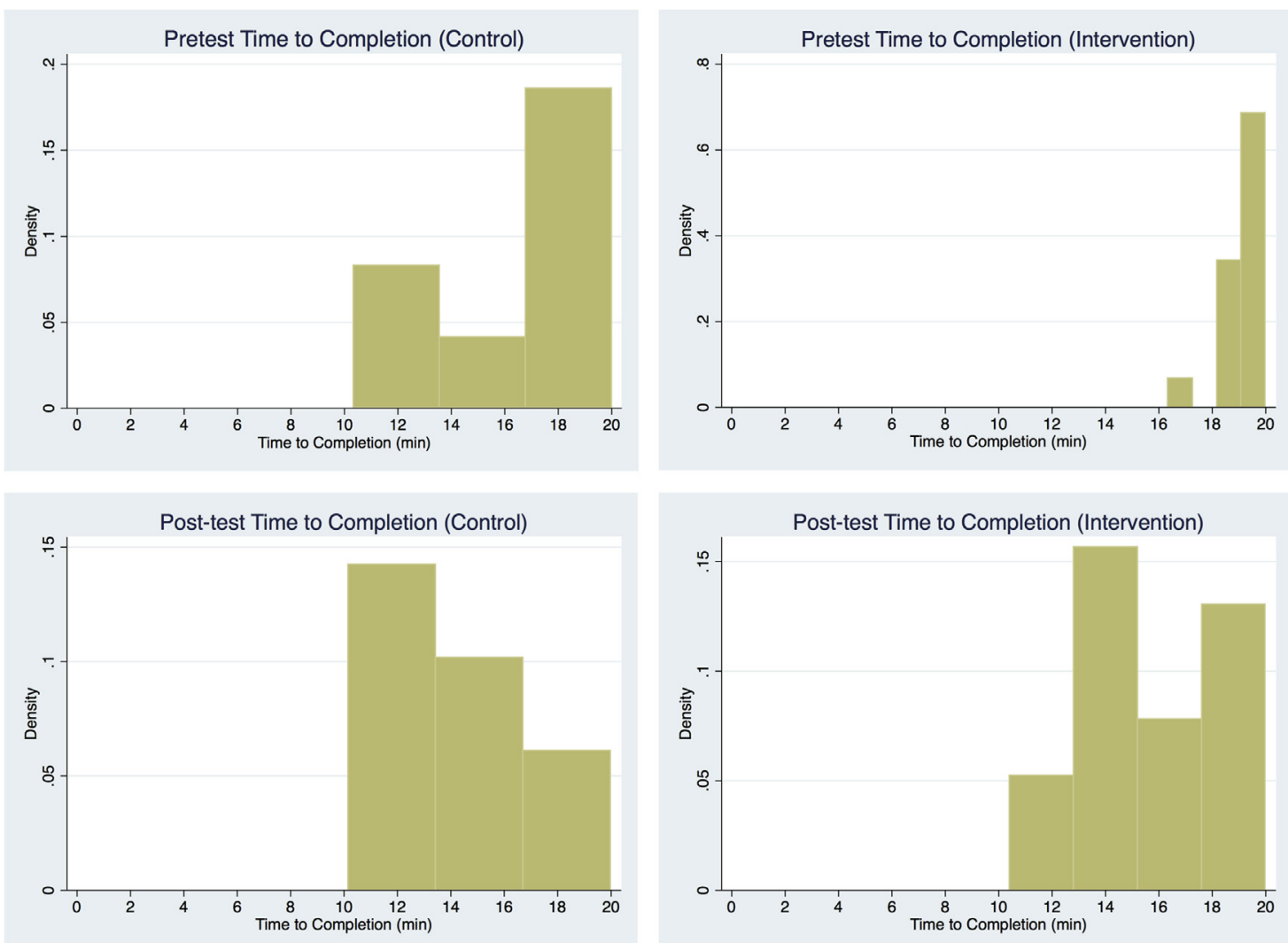

FIGURE E3. Pretest (upper panel) and posttest (lower panel) time to completion histograms (control vs intervention). Total number of subjects, $\mathrm{n}=32$. 


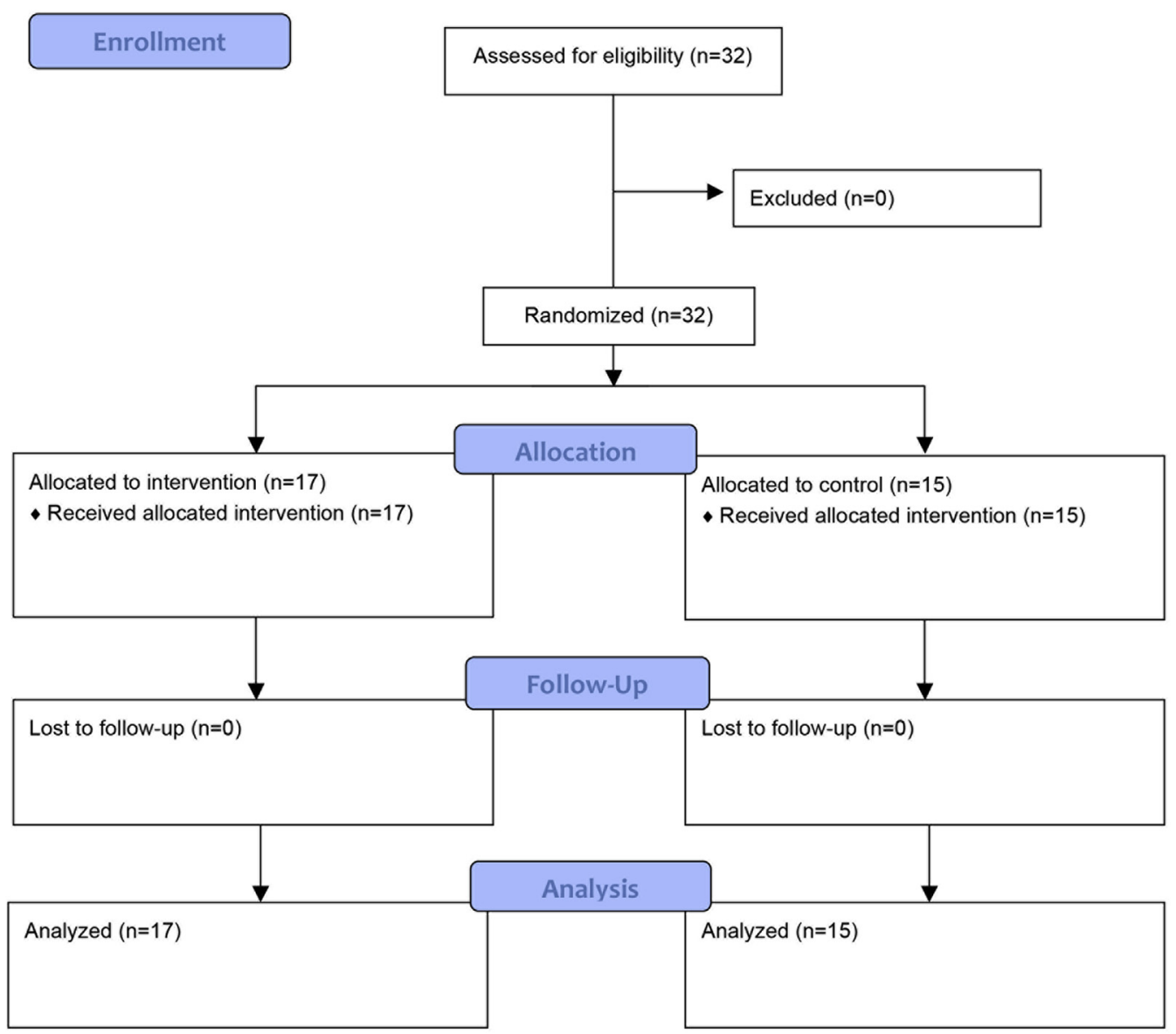

FIGURE E4. CONSORT flow diagram. 